\title{
Features of road-climatic zoning of territories
}

\author{
Vladimir Efimenko ${ }^{1}$, Sergey Efimenko ${ }^{1}$, and Alexey Sukhorukov ${ }^{1, *}$ \\ ${ }^{1}$ Tomsk State University of Architecture and Building, 634003 Tomsk, Russia
}

\begin{abstract}
The paper reflects the Russian and foreign experience of roadclimatic zoning. It demonstrates the need to refine the applicable taxonomic zoning system using the taxonomic scheme "zone - subzone road district". When creating a database for road-climatic zoning, the authors of this paper, in contrast to the scheme adopted in Russia and abroad, take into account territorial patterns of water and heat processes that occur in road structures. The paper justifies soil characteristics for designing pavements in the study area.
\end{abstract}

\section{Introduction}

The presented studies focus on a set of connections and patterns that characterize water and heat processes in subgrades of road facilities in Western Siberia. These processes are affected by natural and climatic conditions that are typical for a particular region.

Being a linear engineering structure, a highway can be located in various natural, climatic, soil and hydrological conditions along its entire length. These conditions are elements of the geographic complex. When designing and constructing highways, experts rely on results of road-climatic zoning to take elements of the geographic complex into account. The road-climatic zoning, which is reflected in technical regulations of the Russian road industry, is based on the results of long-term and thorough research obtained mainly for the road network in the European part of the former USSR. The "zone" taxon is taken as a unit of road-climatic zoning.

Road-climatic zoning of territories has formed the basis for developing building codes, directives and guidelines that are in effect not only in Russia [1,2] but also in China [3, 4], Vietnam [5], the USA [6], Germany [7], the UK, Sweden [8], and other countries, including post-soviet states [9-12].

Regardless of the continent and area occupied by a particular country, road-climatic zoning of territories is based on similar principles and includes three main stages (Fig. 1).

\footnotetext{
* Publishing author: av suhar@mail.ru
} 


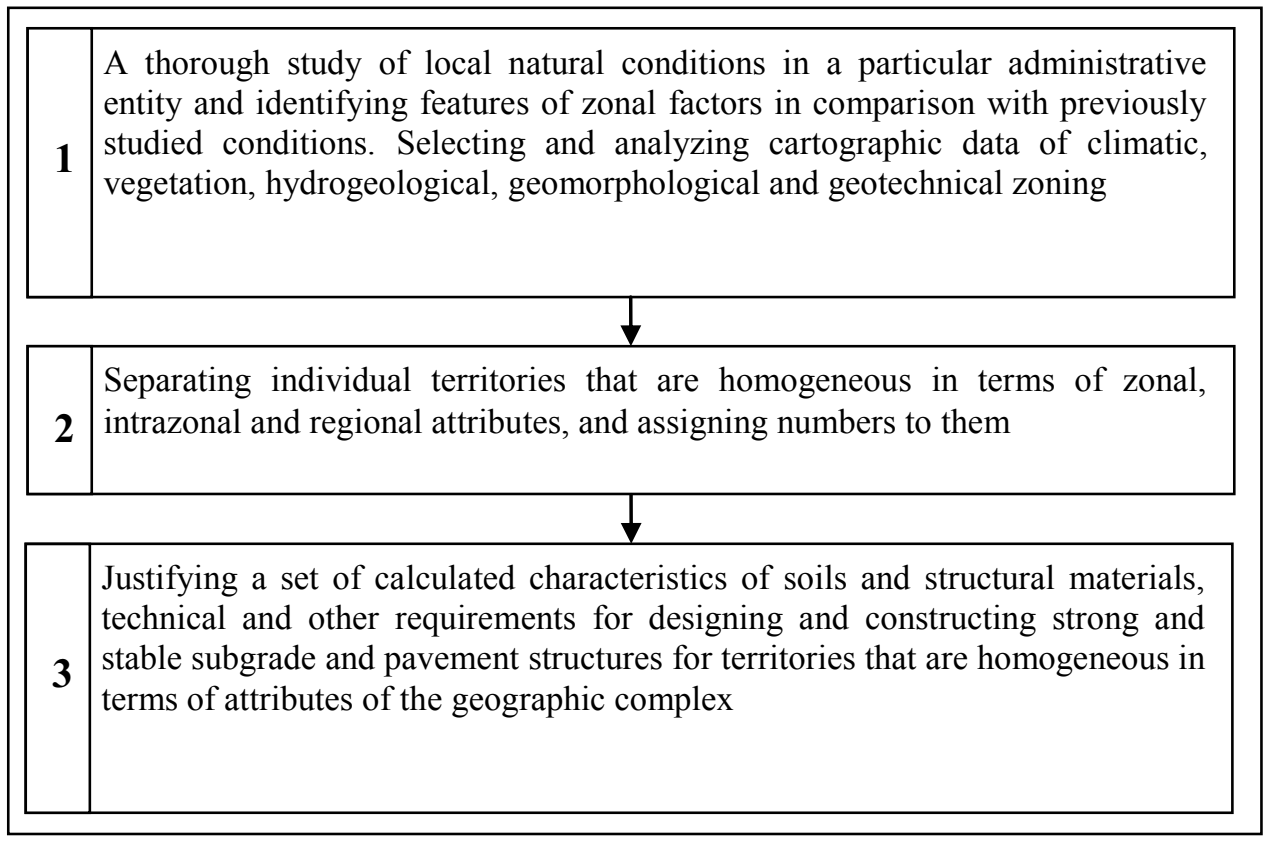

Fig. 1. The main stages of road climatic zoning.

The aim of the study presented in this paper is to ensure the reliable functioning of highways in Western Siberia.

The scientific novelty of the study lies in an effort to identify regional connections and patterns that reflect the influence of the geographic complex on water and heat processes in road structures located in territories that are homogeneous in terms of attributes of the geographic complex.

\section{Problem Statement}

According to the maps given in [1, 2], the territory of the Russian Federation has zonal differentiation and is divided into five road-climatic zones, which differ significantly in terms of natural, climatic and geotechnical conditions. In turn, zones are divided into nine subzones according to sectoral road regulations [1] and into 13 subzones according to the code of rules [2].

The US Interagency Guidance for Road Research [6] identifies 97 physical and geographic districts according to the bearing capacity of soils and their changes under the influence of moisture, as well as according to the availability of road building materials.

By analyzing road-climatic zoning in China, it is possible to conclude that it is based on methodological techniques previously used in the former Soviet Union. This is why there are identical road-climatic zones on the borders between the two countries. Depending on moisture degree, depth of soil freezing, and temperature, the territory of China is divided into seven road-climatic zones [13]. With regard to terrain and climate conditions, 33 subzones and 19 road districts are separated within each road-climatic zone [13]. In terms of climatic conditions, the most extreme road districts are located in the northern China. They belong to road-climatic zone I, which is characterized by temperatures below $0^{\circ} \mathrm{C}$ and the presence of permafrost [13]. 
However, as previously noted by specialists [14-17], the taxonomic "zone-subzone" system does not allow satisfactory division of the climatically diverse Russian territory for ensuring high-quality design and construction of transport infrastructure facilities. Therefore, we suggest that another unit, "road district", should be introduced to the taxonomic zoning system [18-21].

The road district is a genetically homogeneous territory and is a lower element of the taxonomic system "zone-subzone-district". The road district is characterized by specific climate, geology, topography, and other physical elements. Road structures of the road district (primarily subgrades and pavements) located in similar soil and hydrological conditions should be characterized by similar strength and resistance. In this context, strength means the ability to withstand loads without breaking the continuity, while resistance is the ability to change its state so that the strains associated with these changes do not exceed the permissible ones. The concept of subzone implies a territory with uniform microrelief, and the subsystem zone characterizes the earth's surface with uniform distribution of heat and moisture, determining the development of specific interrelated types of soil and vegetation.

It should be noted that a lower unit, "section" taxon, can be used for designing and constructing unique facilities. In case of mass construction, this unit can be neglected.

For road zoning based on the taxonomic scheme "zone - subzone - road district", a special method was developed [14] and tested in five territorial road administrations in Western Siberia. The proposed algorithms and solutions allowed us to localize the boundaries of road-climatic zones I-II, II-III, III-IV, as well as 112 road districts within 14 administrative entities.

\section{Methodology Development}

It should be especially noted that the main task of refining the existing road-climatic zoning practices in relation to individual Russian regions and territories is to separate territories within which the similar road structures are of uniform strength and stability. Target zoning for designing and constructing highways requires the calculation of soil characteristics for introducing subgrade and pavement structures with a specified level of reliability [22].

When calculating required strength of pavements, experts use strength and strain characteristics as the main mechanical soil properties of a subgrade. They include calculated relative moisture content $W_{\text {rel }}$, resilient modulus $E_{s l}$, angle of internal friction $\varphi_{s l}$, and specific cohesion $C_{s l}$. Soil strength and strain characteristics depend on moisture content, density, structure, genesis, and loading conditions. Therefore, they should be determined in the following sequence. Initially, we calculated moisture content and then, using the established relationships, find values of $E_{s l}, \varphi_{s l}$ and $C_{s l}$ at the calculated moisture.

The analyzed results of our studies $[14,15,22]$ allowed us to approach the problem of forecasting design soil characteristics in a way different from the existing probability calculation methods [23]. In particular, in relation to the study area, spring moisture of soils in the working subgrade layer is found to depend to a large extent on its freezing conditions, which can be indirectly estimated by accumulation pattern of negative air temperatures during October-December period.

Considering that a significant part of the study area is characterized by excessive moisture, while soil and climatic conditions predetermine the redistribution of moisture in the subgrade in liquid form, we used a method proposed by professor I. A. Zolotar [23] for calculating moisture content of subgrade soils.

The reliability assessment of the moisture calculation methods used in the research in relation to clay soils in areas with shallow and deep groundwater level was carried out by comparing results of mathematical modeling with field observations of water and heat 
conditions of subgrades in Tomsk and Kemerovo regions. At reliability of forecast $\mathrm{P}=$ 0.95 , the error of moisture calculation was found not to exceed $4 \%$, i.e. to be within the accuracy limits of the measurement by existing methods [10].

For example, based on a set of theoretical and experimental studies, 112 road districts were delineated in Western Siberia. Road-climatic zone II, which has been previously separated according to principle of excessive moisture and normalized in its boundaries, does not include $60 \%$ of the Kemerovo Region, about $20 \%$ of the Altai Territory and at least $20 \%$ of the Novosibirsk Region. We proposed simulation models taking into account patterns of water accumulation in seasonally freezing road structures operating on an area of 2,451.1 thousand $\mathrm{km}^{2}$ of Western Siberia.

As a result of our studies, soil moisture content was calculated for the working subgrade layer in terrains of the second and third types. The correlation between experimentally and theoretically determined values of spring moisture was estimated through the linear correlation coefficient, which was equal to $r=0.82$. For a number of road districts, calculated strength and strain characteristics of clay soils of subgrades were proposed for designing highway pavements. For example, the resilient modulus of loam dusty in climatic conditions of road-climatic zone III, which is recommended in industry-specific standards, is overestimated by about $25-40 \%$ compared to the actual one (depending on the relative soil moisture). In contrast, values of angle of internal friction and specific cohesion are underestimated by $5-30 \%$ and $10-45 \%$, respectively, compared to experimentally determined values.

\section{Conclusion}

Taking the Russian and foreign experience into account, this paper presents the rationale for road-climatic zoning based on the taxonomic scheme "zone - subzone - road district".

Regardless of the continent and the area of a particular country, road-climatic zoning of territories was found to be based on attributes of the geographic complex.

Theoretical and experimental studies allowed us to separate four road-climatic zones (I, II, III, IV) and three subzones (flat, undulated, mountainous), as well as to localize boundaries of 112 road districts within Western Siberia, reflecting distinctive attributes of the geographic complex for each of them.

A set of calculated moisture content, strength and strain values of clay soils used for designing road pavements was justified and refined. For convenience of practical application, values of the characteristics determined according to the established empirical regression relationships are given in tabular form. The presented results can contribute to reliable functioning of highways in various conditions of the geographic complex.

Further research should be aimed at improving the zoning model for separating areas that are homogeneous in terms of attributes of the geographic complex, taking into account water and heat processes in road structures.

\section{References}

1. SP 34.13330.2012. Highways (2013) (in Russian)

2. ODN 218.046-01. Design of flexible pavement (2001) (in Russian)

3. Code of Practice for Highway Routes of the People 's Republic of China: JTG D202006, (2006) (in Chinese)

4. Standard of Climatic Zoning for Highway: JTJ 003-86, (1986) (in Chinese)

5. Highway - Specifications for design: TCVN 4054: 2005, (2005) (in Vietnamese) 
6. "Filing system of physiographic units helps to resolve local design criteria", In: Highway Research News, 51 (1973)

7. Richlinien fur die Standartisierung des Oberbaues von Verkehrsfiuchen: RStO 01, (2001) (in German)

8. D. Groney, The design and performance of road pavements (Transport and road research laboratory, London, 1977)

9. TKP 45-3.03-112-2008, Highways. Flexible pavement. Design rules (2009) (in Russian)

10. VBN B.2.3-218-186-2004, Flexible pavement (2004) (in Ukraine)

11. SNiP RK 3.03-09-2006*, Highways (2014) (in Russian)

12. SNiP RK 32-01:2004, Design. Highways (2004) (in Russian)

13. M. Yinghao, W. Binggang, Journal of Geographical Sciences 14, (2004)

14. V.N. Efimenko, S.V. Efimenko, A.V. Sukhorukov, Sciences in Cold and Arid Regions 7(4) (2015)

15. V.N. Efimenko, S.V Efimenko, A.V. Sukhorukov, IOP Conf. Series: Materials Science and Engineering 71, 012049, (2015)

16. V.M. Sidenko, O.T. Batrakov, M.I. Volkov, Highways (Improvement of design techniques and construction), (1973) (in Russian)

17. T.V. Bobrova, E.A. Bedrin, A.A. Dubenkov Modelirovanie proektnyh reshenij zemljanogo polotna $v$ uslovijah kriolitozony [Simulating of design solutions of the subgrade in the conditions of the permafrost zone] (2016) (in Russian)

18. C.E. Zapata, W.N. Houston, NCHRP report, 602 (2008)

19. L. Chao, W. Yu-lan, X. Jin-liang, Applied Mechanics and Materials, 353-356 (2013)

20. L. Xu, L. Nai-xing, Journal of Chongqing Jiaotong University, 03 (2006)

21. V.A. Yarmolinsky, Vestnik of TSUAB 5 (2014) (in Russian)

22. V.N. Efimenko, S.V. Efimenko, A.V. Sukhorukov, Key Engineering Materials 683 (2016)

23. I.A. Zolotar, Cold Reg. Res. and Eng. Laboratory Hanover (1972) 